\title{
Highly stretchable or extremely soft silicone elastomers? One reaction to make them all - from easily available materials!
}

Pengpeng $\mathrm{Hu}$

DTU

Jeppe Madsen

DTU

Anne Ladegaard Skov ( $\sim$ al@kt.dtu.dk)

Technical University of Denmark https://orcid.org/0000-0003-1223-6638

\section{Article}

Keywords: Platinum Catalyzed Curing Reaction, Polydimethylsiloxane, Versatile Tailoring, Commercial Precursor Polymers

Posted Date: July 15th, 2021

DOI: https://doi.org/10.21203/rs.3.rs-685454/v1

License: (c) (i) This work is licensed under a Creative Commons Attribution 4.0 International License. Read Full License

Version of Record: A version of this preprint was published at Nature Communications on January 18th, 2022. See the published version at https://doi.org/10.1038/s41467-022-28015-2. 
1 Highly stretchable or extremely soft silicone elastomers? One reaction

2 to make them all - from easily available materials!

3

4 Pengpeng $\mathrm{Hu}$, Jeppe Madsen, and Anne Ladegaard Skov*

5 Danish Polymer Centre, Department of Chemical and Biochemical Engineering, Technical University of

6 Denmark, DTU, Søltofts Plads, Building 227, 2800 Kgs, Lyngby, Denmark 
ABSTRACT: An easy curing reaction to prepare silicone elastomers is reported, in which a platinumcatalyzed reaction of telechelic/multi-hydrosilane (Si-H) functional polydimethylsiloxane (PDMS) in the presence of oxygen and water leads to slow crosslinking. This curing chemistry allows versatile tailoring of elastomer properties, which exceed their intrinsic limitations. Both highly stretcha-

5 ble silicone elastomers and extremely soft silicone elastomers are prepared by creating highly entangled elastomers and bottle-brush elastomers from commercial precursor polymers, respectively.

The highly stretchable elastomers can be uniaxially stretched to a maximum strain of $2800 \%$ and their areas can be biaxially extended 180 -fold. The extremely soft silicone elastomers exhibit shear moduli of 1.2-7.4 $\mathrm{kPa}$, depending on composition, values that are comparable to hydrogels and human soft tissues. The reported curing chemistry can be used to prepare a range of silicone elasto-

11 mers with carefully tailored mechanical properties.

\section{INTRODUCTION}

14 Highly stretchable, soft silicone elastomers are of great interest for the fabrication of stretchable 15 electronics, soft actuators, medical devices, and microfluidics. ${ }^{1-5}$ High stretchability provides long-

16 term device stability in various distortion scenarios and permits exceptional deformations. Signifi17 cant effort has been devoted to preparing silicone elastomers with a combined softness and elastic18 ity resembling that of human soft tissue for use in soft robotics. ${ }^{6,7}$

19 Silicone elastomers are typically prepared by crosslinking linear polymers with cross-linkers. Figure 1a presents one of the most commonly used crosslinking reactions-i.e., the hydrosilylation re-

21 action of telechelic vinyl functional polydimethylsiloxane (PDMS) with a multi-hydrosilane (Si-H)

22 functional cross-linker in the presence of a platinum catalyst. ${ }^{8}$ Based on classical curing chemistry, 23 network strands possess the same size and structure as the precursor polymers which ultimately 24 determine the mechanical properties of the silicone elastomers. The ultimate extensibility of the 
resulting silicone elastomers is proportional to $M^{0.5}$ based on the Kuhn model, where $M$ is the average molar mass of network strands. ${ }^{9}$ The ultimate extensibility is usually less than $900 \%$, and it is difficult to further increase this value by using longer precursor polymers, since they would bring difficulties to the fabrication process due to their high viscosity. ${ }^{10}$ The elastic modulus of the silicone elastomers is determined by the crosslinking density-namely, the molar density of mechanically active strands $v=\rho / M$, where $\rho$ is the density. However, the lowest achievable elastic modulus for

31 ideal elastomer networks is around 0.6 MPa due to the fact that entanglements in the cross-linked networks act as topological crosslinks once the molecular weight of network strands ( $M$ ) exceeds the entanglement molecular weight. ${ }^{11}$

Several strategies have been explored for overcoming limitations on the ultimate extensibility and softness of silicone elastomers. For example, elastomers prepared from long precursor polymers in solution and subjected to solvent evaporation after curing, supramolecular elastomers with movable cross-links, and concatenated ring elastomers have all been developed to improve ultimate extensibility. ${ }^{12-17}$ Approaches such as adding external sol molecules, sparse crosslinking, and crosslinking bottle-brush PDMS have also been used to prepare soft silicone elastomers. ${ }^{18-23}$ While the above strategies improve elastomer extensibility or softness to some extent, they either increase

41 process complexity or lead to mechanical instabilities in the resulting elastomers. What is more, none of them are versatile enough to enable the preparation of silicone elastomers that are both highly stretchable and very soft. There is thus a lack of available chemistries capable of efficiently preparing silicone elastomers with superior stretchability and softness.

Silicone elastomers have been prepared from $\mathrm{Si}-\mathrm{H}$ functionalized polymers at $250^{\circ} \mathrm{C}$ in air, where the crosslinking mechanism was found to originate from oxidative crosslinking of Si-H groups in the presence of oxygen. ${ }^{24}$ In this study, silicone elastomers are prepared from PDMS with telechelic/multiple $\mathrm{Si}-\mathrm{H}$ groups and a platinum catalyst in air at the much lower temperature of $100^{\circ} \mathrm{C}$ (see Figure $1 \mathrm{~b}$ ). In contrast to classical curing chemistries where the network strands are 
50 directly related to the length of the precursor polymers, the curing chemistry presented here, when

51 combined with the hydrosilylation reaction, allows network strands to be tailored from normal lin52 ear precursors during the curing process. Specifically, we report highly stretchable silicone elasto-

53 mers with ultra-long network strands and extremely soft silicone elastomers with bottle-brush 54 strands, both of which are easily prepared from commercially available linear precursors. Both 55 novel silicone elastomers are based on sequential crosslinking mechanisms in one-pot reactions, 56 where the fast hydrosilylation reaction is followed by a slow crosslinking of residual $\mathrm{Si}-\mathrm{H}$ functional 57 groups. This allows independent control of network strand size and structure, as well as of cross58 linking. 
(a) Conventional curing reaction

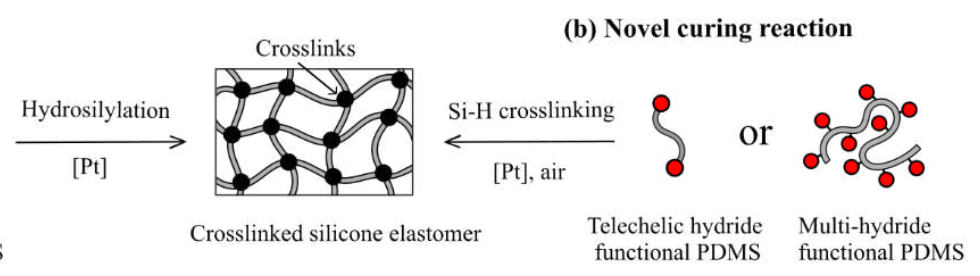

(c) One-pot reaction towards highly stretchable silicone elastomer

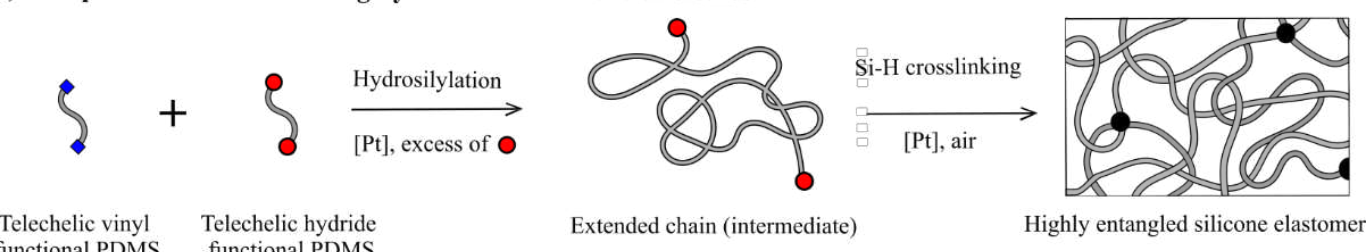
functional PDMS functional PDMS

(d) One-pot reaction towards extremely soft silicone elastomer

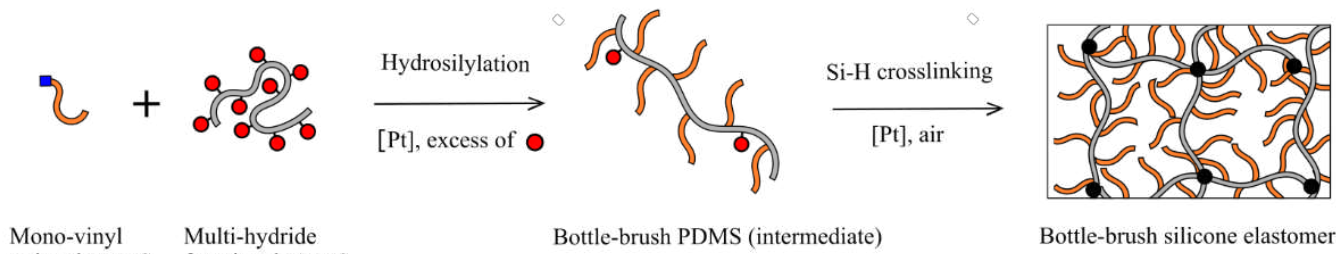
functional PDMS functional PDMS

Chemical structure of individual components

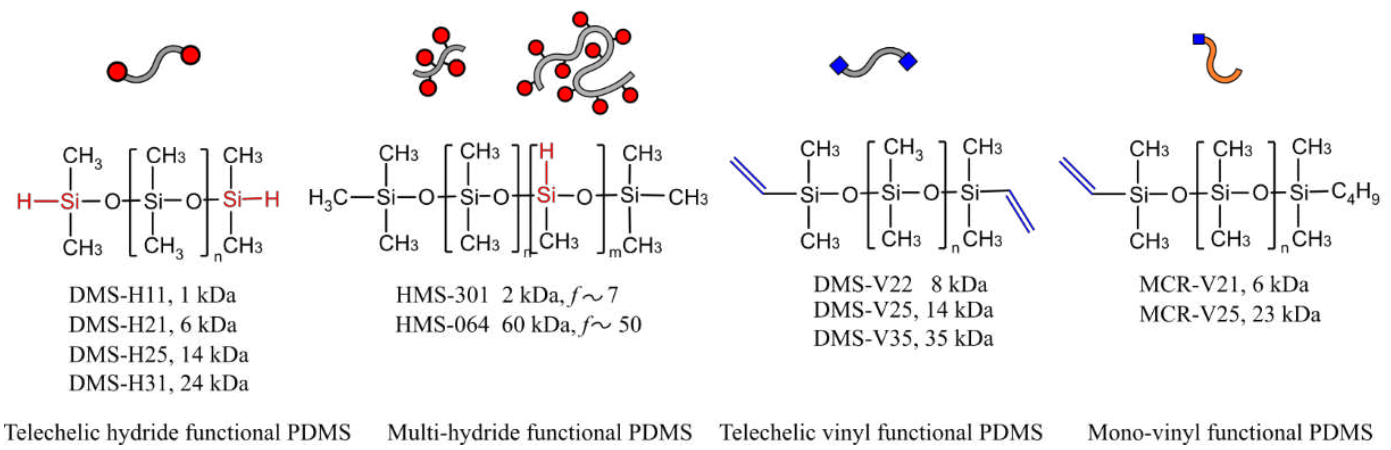

61 Figure 1. (a) Conventional curing reaction to prepare silicone elastomers. ${ }^{8}$ (b) Novel curing reaction to prepare silicone elastomers. (c) Highly stretchable silicone elastomers and (d) extremely soft silicone elastomers prepared from a one-pot curing reaction by combining hydrosilylation and subsequent $\mathrm{Si}-\mathrm{H}$ crosslinking reactions.

\section{RESULTS AND DISCUSSION}


further studies in order to elucidate the mechanism of this formation.

Hydrosilanes readily undergo hydrolysis and alcoholysis reactions with water and alcohols, respectively, under basic or strongly acidic conditions or in the presence of radicals, metals, or transition metal complexes. ${ }^{25,26}$ In the presence of a platinum catalyst and water, telechelic Si-H functional PDMS can thus be hydrolyzed into $\mathrm{Si}-\mathrm{OH}$, which may further undergo condensation to form extended chains. However, the hydrolysis and condensation reactions cannot account for the formation of elastomers from telechelic Si-H functional PDMS in a conventional manner. Instead, obtaining elastomers from telechelic Si-H functional PDMS requires either the formation of concatenated rings through intramolecular condensation reactions or some other unexplored crosslinking reaction. ${ }^{15,17}$ Water and oxygen are the possible reactants in the curing reaction with Si-H-containing precursor PDMS. The reaction was therefore carried out under conditions in which water and oxygen content could be carefully controlled. Specifically, in a series of experiments, a representative telechelic Si-H functional PDMS (DMS-H11, $M_{\mathrm{n}}=1 \mathrm{kDa}$ ) was heated at $100^{\circ} \mathrm{C}$ for $48 \mathrm{~h}$ in a sealed flask under each of the following reaction conditions: dry $\mathrm{N}_{2}$ (a dried sample under dried nitrogen), wet $\mathrm{N}_{2}$ (a sample containing water with $\sim 4$ molar equivalent of hydrosilanes under dried nitrogen), dry air (a dried sample under dried air), and wet air (a sample containing water with $\sim 4$ molar equivalent of hydrosilanes under dried air). DMS-H11 was converted into a solid elastomer only under wet air conditions. As measured by ${ }^{1} \mathrm{H}$ NMR, the conversion efficiency of Si-H groups for the three liquid products under dry $\mathrm{N}_{2}$, wet $\mathrm{N}_{2}$, and dry air conditions were found to be $6.6 \%, 29.5 \%$, and $52.9 \%$, respectively (Figure $2 \mathrm{a}$ ). These findings indicate that both water and oxygen participate in the reaction. A peak at $2.27 \mathrm{ppm}$ in the ${ }^{1} \mathrm{H}$ nuclear magnetic resonance (NMR) spectrum of the sample from the wet $\mathrm{N}_{2}$ atmosphere is assigned to a Si-OH structure (Figure 2a), suggesting a hydrolysis process of $\mathrm{Si}-\mathrm{H}$ during the reaction. ${ }^{27} \mathrm{~A}$ further condensation process of $\mathrm{Si}-\mathrm{OH}$ results in chain extension, as evidenced by the increased molecular weight of the sample (Figure S1, ESI). Another new peak that appears at $3.47 \mathrm{ppm}$ (Figure $2 \mathrm{a}$ ) on the ${ }^{1} \mathrm{H}$ spectrum of the sample from dry air 

in the absence of a platinum catalyst. ${ }^{24}$ The presence of this silyl ether suggests that branched chains are formed during the oxidation of $\mathrm{Si}-\mathrm{H}$. The integration of the ${ }^{1} \mathrm{H}$ spectrum shows that the amount of hydrogen on silyl ether only accounts for $1.4 \%$ of the Si-H loss (Table S3, ESI), suggesting that mal loss of $\mathrm{Si}-\mathrm{H}(6.6 \%$, Figure $2 \mathrm{a})$ under dry $\mathrm{N}_{2}$ conditions is most likely due to trace amounts of air and water in the starting polymer, as well as a small amount of vinyl groups associated with the 103 platinum catalyst.
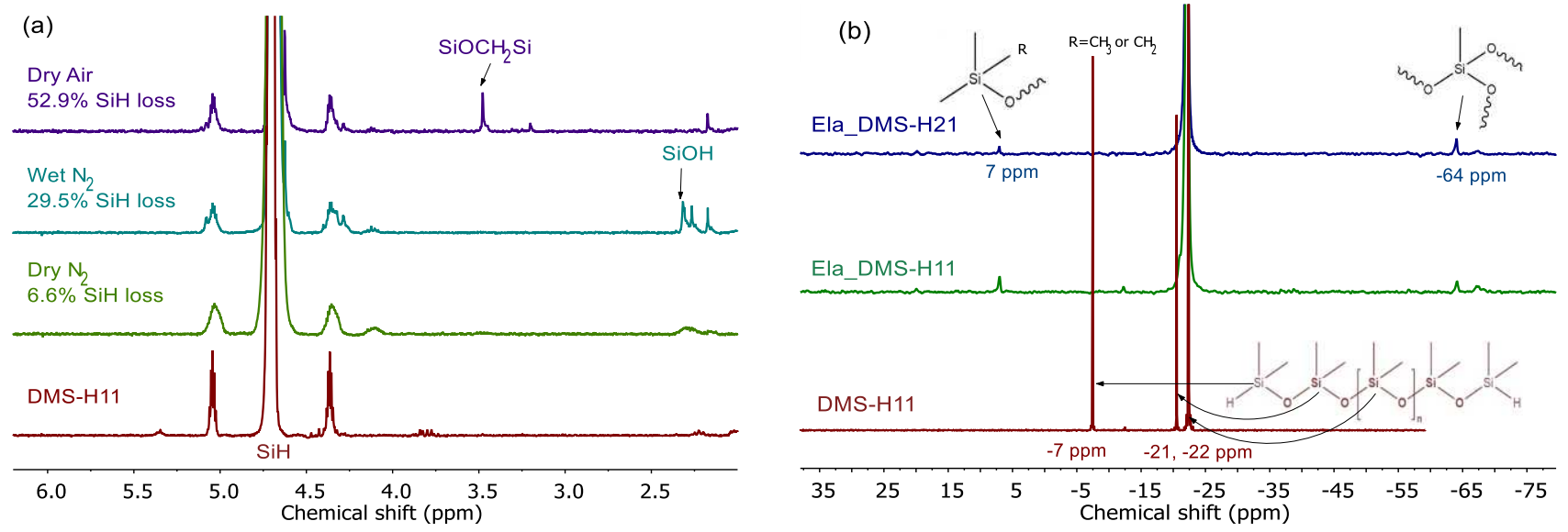

(c)
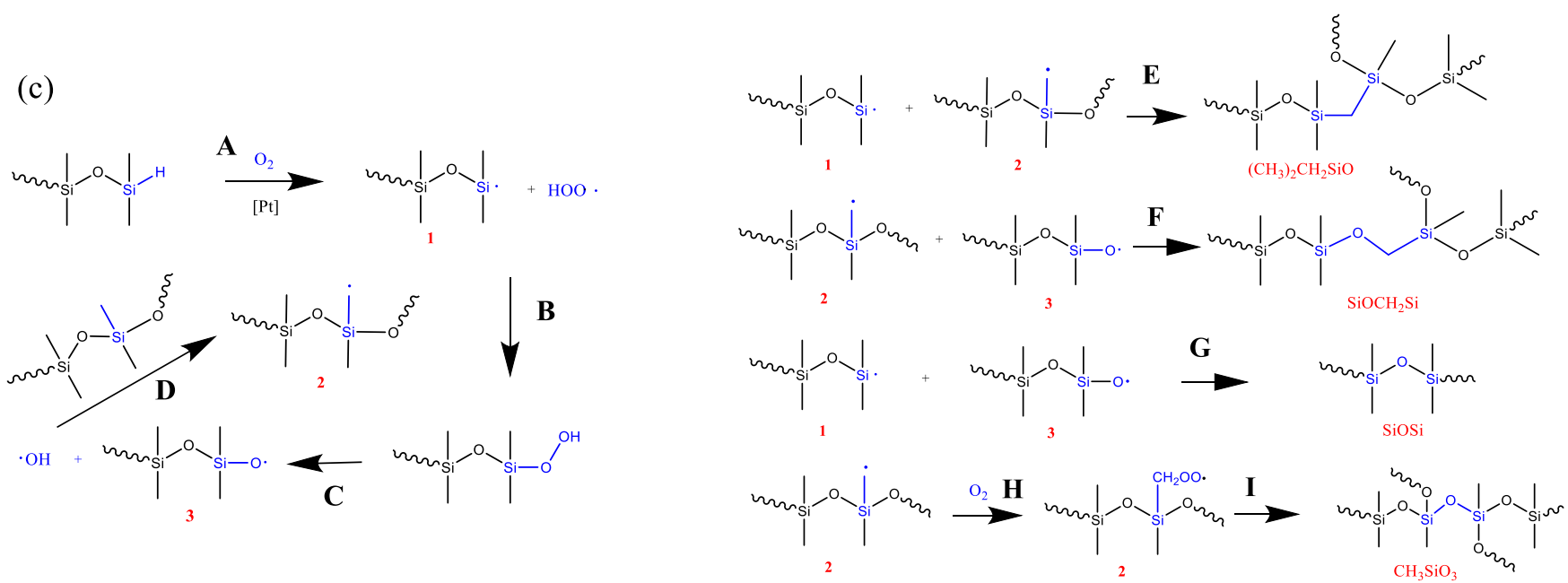

104 Figure 2. (a) ${ }^{1} \mathrm{H}$ NMR spectra of a telechelic Si-H functional PDMS (DMS-H11) and its reaction products after 105 heating at $100^{\circ} \mathrm{C}$ for $48 \mathrm{~h}$ under dry $\mathrm{N}_{2}$, wet $\mathrm{N}_{2}$, and dry air conditions, respectively. (b) ${ }^{29} \mathrm{Si}$ solid-state NMR spectra 
of elastomers (Ela_DMS-H11 and Ela_DMS-H21) and a precursor polymer (DMS-H11). (c) Proposed mechanism

107 of crosslinking Si-H functional groups in the presence of oxygen and a catalyst.

108

109

110

111

112

113

114

115

116

Direct investigations of the chemical composition of solid elastomers cured under a normal air atmosphere and a precursor polymer DMS-H11 were performed using ${ }^{29}$ Si solid-state NMR. Figure 2 b shows that a peak at -7 ppm on the spectrum of the precursor polymer is assigned to Si-H functional groups. ${ }^{28}$ This peak vanishes on the spectra of the elastomers, suggesting an efficient conversion of Si-H after curing. New peaks located at $7 \mathrm{ppm}$ and $-64 \mathrm{ppm}$ are observed on spectra of the elastomers and are assigned to $\left(\mathrm{CH}_{3}\right)_{3} \mathrm{SiO}\left(\right.$ or $\left.\left(\mathrm{CH}_{3}\right)_{2} \mathrm{CH}_{2} \mathrm{SiO}\right)$ and $\mathrm{CH}_{3} \mathrm{SiO}_{3}$, respectively. ${ }^{28-30}$ Since the hydrolysis of $\mathrm{Si}-\mathrm{H}$ and further condensation of $\mathrm{Si}-\mathrm{H}$ with $\mathrm{Si}-\mathrm{OH}$ would only produce more backbone chains $\left(-\left(\mathrm{CH}_{3}\right)_{2} \mathrm{SiO}-\right)$, the newly formed structures are the result of oxidation of Si-H functional groups. Integration of the spectra shows that Si atoms associated with these newly formed structures account for $1.5-2.5 \%$ of Si atoms in the elastomers(Table S4, ESI), suggesting that these oxidized structures play a major role in crosslinking.

Based on the observations above, it is clear that oxidation of Si-H plays a role in creating branched chains to form networks, as hydrolysis and subsequent condensation of telechelic chains would only produce longer, linear chains. The oxidation processes are proposed as follows. Si-H functional groups are turned into silyl radicals $\left.\left(\mathrm{O}_{(\mathrm{CH}}\right)_{2} \mathrm{Si} \cdot\right)$ through hydrogen abstraction in the presence of air (Figure 2c-A). ${ }^{31,32}$ After further oxidation processes, the silyl radicals are transformed into $\mathrm{O}\left(\mathrm{CH}_{3}\right)_{2} \mathrm{SiO} \cdot($ Figure 2c-B and $\mathrm{C}) .^{24}$ Oxidation processes also happen on methyl groups of silicones: oxygen initially generates a carbon radical $\left(\mathrm{SiCH}_{2}{ }^{*}\right)$ by hydrogen atom abstraction (Figure 2c-D) $)^{33,34}$. Branching structures like $\mathrm{SiCH}_{2} \mathrm{Si}$ and $\mathrm{SiOCH}_{2} \mathrm{Si}$ are formed by combinations of $\mathrm{SiCH}_{2} \cdot$ with $\mathrm{O}\left(\mathrm{CH}_{3}\right)_{2} \mathrm{Si} \cdot$ and $\mathrm{O}\left(\mathrm{CH}_{3}\right)_{2} \mathrm{SiO} \cdot$, respectively (Figure 2c-E and F). A combination of $\mathrm{O}\left(\mathrm{CH}_{3}\right)_{2} \mathrm{Si} \cdot$ and $\mathrm{O}\left(\mathrm{CH}_{3}\right)_{2} \mathrm{Si}-\mathrm{O} \cdot$ only produces extended chains via the formation of SiOSi (Figure 2c-G). Further oxidation of $\mathrm{SiCH}_{2}$. leads to the creation of $\mathrm{SiCH}_{2} \mathrm{OO} \cdot$, which enables the formation of $\mathrm{SiO}_{3} \mathrm{CH}_{3}$ by a self- 
132 It should be noted that the same radicals mentioned above were also used to explain crosslinking 133 during the oxidization of $\mathrm{Si}-\mathrm{H}$ functional PDMS at high temperature $\left(250^{\circ} \mathrm{C}\right)$ in the absence of a cat134 alyst, in which a silyl ether ( $\left.\mathrm{Si}-\mathrm{O}-\mathrm{CH}_{2}-\mathrm{Si}\right)$ structure was the main oxidized structure produced. ${ }^{24}$ In 135 our work, however, the oxidation process is faster and occurs at a much lower temperature due to 136 the use of a platinum catalyst; the main oxidized structures produced are $\left(\mathrm{CH}_{3}\right)_{2} \mathrm{CH}_{2} \mathrm{SiO}_{\mathrm{O}}$ and $\mathrm{CH}_{3} \mathrm{SiO}_{3}$. $137 \mathrm{Si}-[\mathrm{Pt}]-\mathrm{H}$ complex is known to form by oxidative addition, ${ }^{35-37}$ and [Pt]-oxygen complex has been 138 reported to significantly promote platinum catalyzed hydrosilylation reactions. ${ }^{38,39}$ These com139 pounds may allow the reaction with oxygen to occur at moderate temperatures, thereby changing 140 the main oxidized structures produced.

141 This curing chemistry can be extended to the curing of multifunctional Si-H functional PDMS, where 142 both hydrolysis/condensation and oxidation reactions may contribute to crosslinking. The pre143 pared elastomers listed in Table 1 are named according to the precursor polymer used. Overall, the 144 prepared silicone elastomers show tensile strains of 70-360\%, Young's moduli of 0.3-0.6 MPa, and 145 tensile strengths of 0.2-0.6 MPa. These mechanical properties are comparable to those of the two 146 conventional silicone elastomers prepared via the classical curing route. ${ }^{10}$ 
Table 1. Silicone elastomers prepared from telechelic/multi Si-H functional PDMS in presence of a platinum-divinyl tetramethyldisiloxane complex. Conventional elastomers (Ref_DMS-V25 and Ref_DMS-V41) were prepared as references from telechelic vinyl functional PDMS, a multi-Si-H functional PDMS, and a platinum catalyst.

\begin{tabular}{|l|l|l|l|l|}
\hline Sample & $\begin{array}{l}\text { Precursor length } \\
(\mathrm{kDa})\end{array}$ & $\begin{array}{l}\text { Tensile strain } \\
(\%)\end{array}$ & $\begin{array}{l}\text { Tensile strength } \\
(\mathrm{MPa})\end{array}$ & $\begin{array}{l}\text { Young's modulus } \\
(\mathrm{MPa})\end{array}$ \\
\hline Ela_DMS-H11 & 1 & 71 & 0.24 & 0.37 \\
\hline Ela_DMS-H21 & 6 & 70 & 0.35 & 0.60 \\
\hline Ela_DMS-H25 & 14 & 235 & 0.49 & 0.40 \\
\hline Ela_DMS-H31 & 24 & 363 & 0.46 & 0.29 \\
\hline Ela_HMS-064 & 60 & 118 & 0.52 & 0.52 \\
\hline Ref_DMS-V25 & 14 & 127 & 0.54 & 0.84 \\
\hline Ref_DMS-V41 & 35 & 482 & 0.44 & 0.19 \\
\hline
\end{tabular}

153 In order to compare the reaction kinetics of the Si-H functional PDMS system with those of the hy154 drosilylation reaction between $\mathrm{Si}-\mathrm{H}$ and vinyl groups, platinum-catalyzed reactions of mono-Si-H 155 functional PDMS and mono-Si-H functional PDMS with mono-vinyl functional PDMS, respectively, 156 were conducted at $100^{\circ} \mathrm{C}$. The total concentration of functional groups was the same for both reac157 tions. Figure 3a shows that the reaction of mono-Si-H functional PDMS takes $6 \mathrm{~h}$ to complete 100\%, 158 compared to $2 \mathrm{~min}$ for the hydrosilylation reaction. In addition, the reaction of mono-Si-H functional 159 PDMS products a fraction of products that are more than 10-time molecular weight of precursor 160 polymers (Figure 3a). This is consistent with the branching nature of Si-H oxidation. In comparison, 161 the hydrosilylation reaction of mono-Si-H functional PDMS with mono-vinyl functional PDMS exclu162 sively produces chains with double initial molecular weight (Figure 3a). 

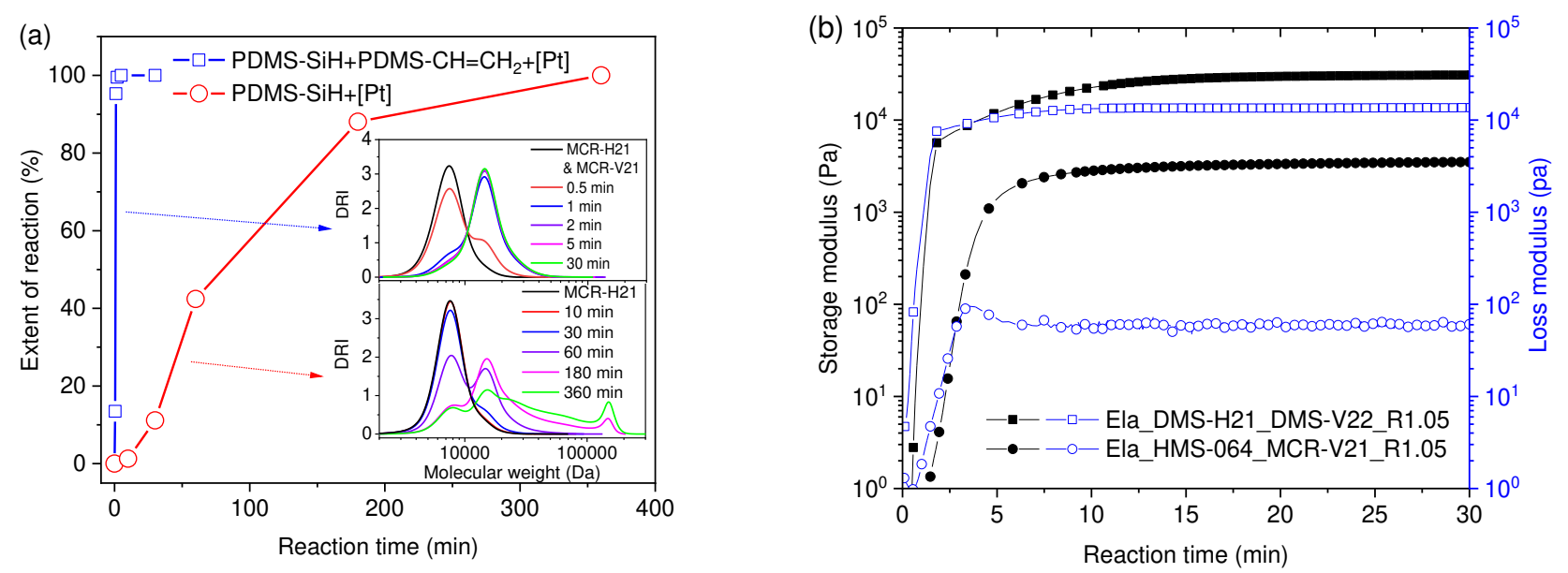

163 Figure 3 (a) Reaction progression over time for the platinum-catalyzed reactions at $100^{\circ} \mathrm{C}$ of mono-hydrosilane 164 functional PDMS, and mono-hydrosilane functional PDMS with mono-vinyl functional PDMS (stoichiometric 165 amounts of hydride and vinyl). The inserts show molecular weight distributions over time during the two reactions. (b) Dependence of storage and loss moduli of representative highly stretchable and extremely soft silicone elastomers on curing time measured at $100^{\circ} \mathrm{C}, 1 \mathrm{~Hz}$, and with a fixed strain of $1.0 \%$.

169 Curing chemistries for highly stretchable/extremely soft silicone elastomers.

170 Preparing silicone elastomers with long strands is one way to efficiently obtain high stretchability.

171 However, doing so using conventional curing chemistry requires exceptionally long precursor poly-

172 mers whose high viscosity brings difficulties to fabrication process. ${ }^{9,40}$ Here, highly stretchable sili-

173 cone elastomers are prepared from a platinum-catalyzed reaction between telechelic Si-H func-

174 tional PDMS and telechelic vinyl functional PDMS using a small excess of Si-H groups (Figure 1c). In

175 a one-pot reaction, both the hydrosilylation reaction between $\mathrm{Si}-\mathrm{H}$ and vinyl groups and the water

176 and oxygen-mediated crosslinking of Si-H (see above) take place. Due to the significant kinetic ad-

177 vantage of the hydrosilylation reaction over Si-H crosslinking (Figure 3a), the hydrosilylation reac-

178 tion is expected to proceed to high conversion before any significant crosslinking occurs. Assuming

179 the two reactions happen strictly in sequence, the hydrosilylation reaction results in extended 180 chains which are subsequently cross-linked into elastomers through the reaction of excess Si-H with 
oxygen and water. In this case, the average molar mass of the network strands can be expressed using equation 1 (derived from Equation S1, ESI):

183

$$
M_{\text {extended }}=\frac{R M_{\mathrm{DMS}-\mathrm{H}}+M_{\mathrm{DMS}-\mathrm{V}}}{R-1}
$$

184

185

186 where $M_{\mathrm{DMS}-\mathrm{H}}$ is the molecular weight of telechelic Si-H functional PDMS, $M_{\mathrm{DMS}-\mathrm{V}}$ is the molecular weight of telechelic vinyl functional PDMS, and $R$ is the molar ratio of the Si-H-to-vinyl functional groups. According to equation 1, even when the values of $M_{\mathrm{DMS}-\mathrm{H}}$ and $M_{\mathrm{DMS}-\mathrm{V}}$ are relatively low, ultra-long network strands can be achieved by setting $R$ close to unity.

Expanding the diameter of the polymer by attaching polymer brushes is a known method for diluting entanglements without markedly increasing chain stiffness. The resulting bottle-brush elastomers are intrinsically soft, with shear moduli of 1-100 kPa. ${ }^{21,22,41}$ However, preparing bottle-brush elastomers generally involves relatively complex multistep syntheses, including preparation of bottle-brush polymers followed by subsequent crosslinking reactions. ${ }^{23,41}$ Here, soft silicone elastomers are obtained by preparing bottle-brush elastomers through a platinum-catalyzed, one-pot curing reaction of multi-Si-H functional PDMS with mono-vinyl functional PDMS in the presence of excess of Si-H functional groups (Figure 1d). During the reaction, bottle-brush polymers are preferentially formed by grafting mono-vinyl functional PDMS onto the multi-Si-H functional PDMS through hydrosilylation. The resulting bottle-brush polymers are subsequently cross-linked into bottlebrush elastomers through the relatively slow crosslinking of $\mathrm{Si}-\mathrm{H}$ in the presence of oxygen and water. Side chain lengths, and thus polymer diameter, are governed by the length of the mono-vinyl functional PDMS. Assuming crosslinking of Si-H takes place strictly after full side chain grafting, the molecular weight between Si-H groups on the bottle-brush chains can be determined as:

$$
M_{\mathrm{c} \_ \text {SiH }}=\frac{M_{\mathrm{brush}}}{f_{\mathrm{brush}}+1}
$$


203 where $M_{\text {brush }}$ (Equation S3, ESI) and $f_{\text {brush }}$ (Equation S4, ESI) are the molecular weight and number

204 of excess hydrides per chain, respectively, after full side chain grafting.

205 Representative curing reactions for preparing highly stretchable, extremely soft elastomers were 206 investigated by tracing the evolution of the storage and loss moduli during the two curing reactions 207 (Figure $3 \mathrm{~b}$ ). Gel points are reached within $5 \mathrm{~min}$ at $100^{\circ} \mathrm{C}$, suggesting fast curing processes.

209 Properties of highly stretchable silicone elastomers

210 A number of stretchable silicone elastomers were prepared using different hydrosilane-to-vinyl211 functional polymer ratios as well as polymers of different molecular weights, as shown in Table 2. 212 Figure 4a shows that, when using the same precursor polymers DMS-H21 and DMS-V22, the tensile 213 strain increases from $1040 \%$ to $2400 \%$ when $R$ decreases from 1.15 to 1.05 . Tensile strain can be 214 further increased to $2800 \%$ by using longer starting polymers DMS-H25 and DMS-V25. Longer ex215 tended chains improve tensile strain by enabling larger slippage lengths upon deformation (Table 216 2). The Kuhn model is widely used to estimate the ultimate extensibility of elastomers as $\lambda_{\max }=$ $217 L / h$, where $L$ is the strand length in a fully stretched state, and $h$ is the strand length in a random 218 coil state. $^{9} \lambda_{\max }$ is thus proportional to $M^{0.5}$ based on the relations of $L \propto M$ and $h \propto M^{0.5}$. A linear 219 relation between $\lambda_{\max }$ and $M_{\text {theo }}^{0.5}$ complies with the Kuhn model (Figure S3), suggesting that equa220 tion 1 is a valid description of the molar mass of the network strands, which supports the proposed 221 curing route. Silicone elastomers with tailored stretchability can thus be realized by designing 222 strand lengths based on equation 1. Elastomers' linear viscoelastic responses are shown in Figure 223 4b. The storage modulus of the conventional elastomer reaches a plateau at low frequencies, while 224 the storage moduli of the highly stretchable elastomers continue to decrease as the frequency ap225 proaches zero. This unusual behavior is explained by stress relaxation from entanglements of highly 226 extended strands upon deformation. Stretchable elastomers are often biaxially stretched in practi227 cal use. ${ }^{42,43}$ Figure 4c shows the area of stretchable silicone elastomer, Ela_DMS-H21_DMS- 
V22_R1.05, is biaxially extended 180-fold from an initial state-20 times greater extension than that

229 of the conventional silicone elastomer Ref_DMS-V41. This significantly enhanced stretchability

230 demonstrates the very high mechanical integrity of the elastomers studied here.

Table 2. Specifications for studied highly stretchable silicone elastomers.

\begin{tabular}{|l|l|l|l|l|l|}
\hline Samples & $\begin{array}{l}M_{\text {DMS-H }} \\
(\mathrm{kDa})\end{array}$ & $\begin{array}{l}M_{\text {DMS-V }} \\
(\mathrm{kDa})\end{array}$ & $R$ & $\begin{array}{l}M_{\text {extended }} \\
(\mathrm{kDa})\end{array}$ & $\lambda_{\max }$ \\
\hline Ela_DMS-H21_DMS-V22_R1.05 & 6 & 8 & 1.05 & 286 & 2493 \\
\hline Ela_DMS-H21_DMS-V22_R1.10 & 6 & 8 & 1.10 & 146 & 1602 \\
\hline Ela_DMS-H21_DMS-V22_R1.15 & 6 & 8 & 1.15 & 99 & 1142 \\
\hline Ela_DMS-H25_DMS-V25_R1.05 & 14 & 14 & 1.05 & 574 & 2864 \\
\hline
\end{tabular}
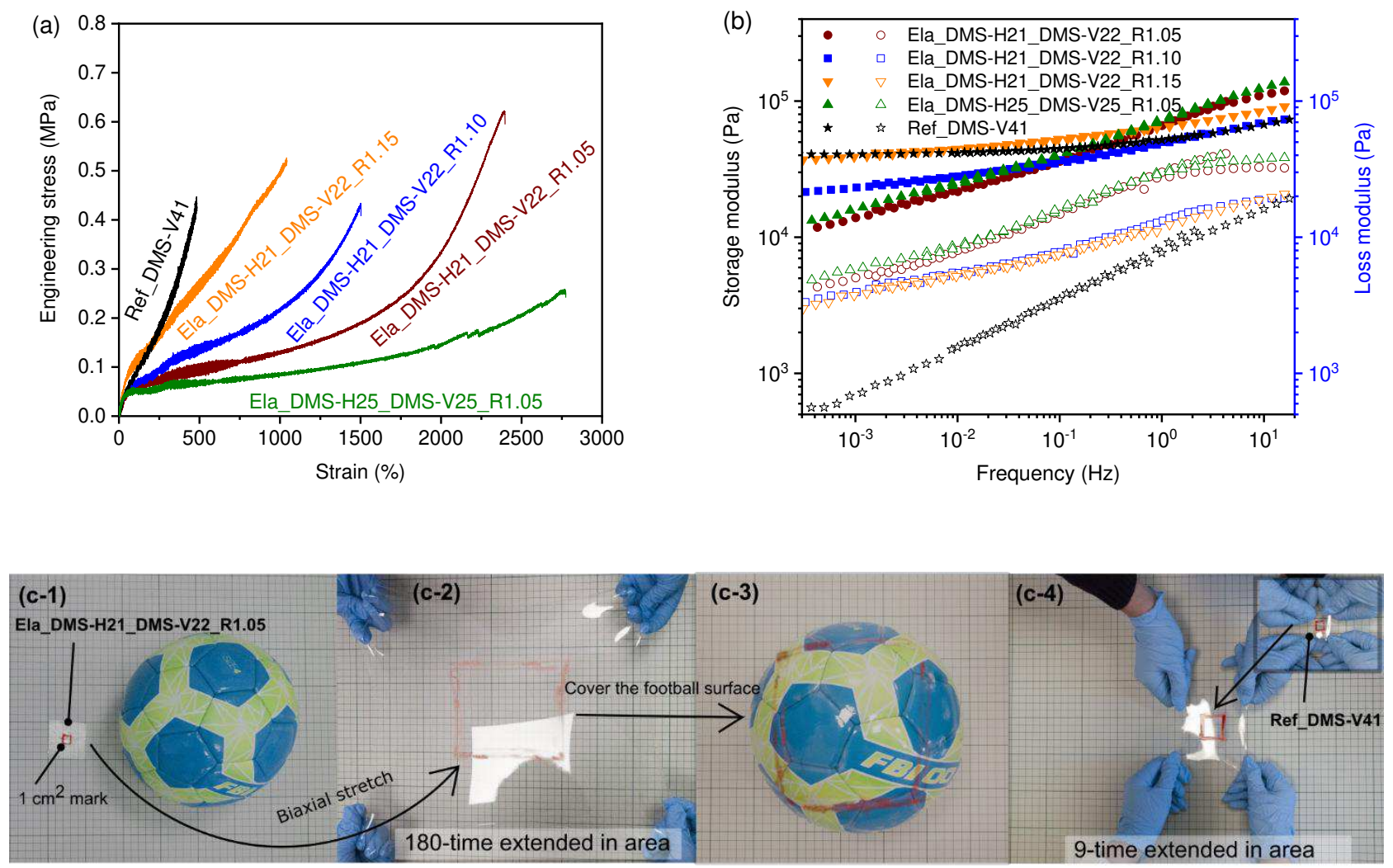
234 Figure 4. Properties of highly stretchable silicone elastomers and a conventional silicone elastomer. (a) Uniaxial

235 stress-strain curves. (b) Frequency dependence of storage and loss moduli measured at room temperature. (c) Bi236 axial stretching. (c-1) The highly stretchable silicone elastomer is marked with a red $1 \mathrm{~cm}^{2}$ square; (c-2) the area of 237 the same film is manually extended 180-fold. (c-3) The extended film subsequently covers the surface of a football 238 with a diameter of $21 \mathrm{~cm}$. (c-4) The conventional silicone elastomer marked with a $1 \mathrm{~cm}^{2}$ red square is extended to 239 a maximum of 9 times its original area.

241 Properties of extremely soft silicone elastomers

242 A range of bottle-brush elastomers were fabricated according to the formulations in Table 3. Shear 243 moduli of the prepared elastomers $(G)$ are taken to be equivalent to the plateau values of storage 244 moduli at low oscillatory frequency (Figure 5a), and decrease from $7.4 \mathrm{kPa}$ to $1.2 \mathrm{kPa}$ when using 245 either smaller $R$ or 4-fold longer side chains. Such low shear moduli are comparable to those of 246 hydrogels and human soft tissue. ${ }^{44}$ Linear viscoelastic responses (Figure 5a) show that the prepared 247 elastomers have near frequency-independent storage moduli, making them resemble a perfect rub248 ber. Table 3 shows that the molecular weights of bottle-brush network strands $\left(M_{\mathrm{c}}\right)$ (Equation S6, 249 ESI) are larger than the average molecular weight between Si-H groups on the bottle-brush chains $250\left(M_{\mathrm{C}_{-} \mathrm{SiH}}\right)$. Specially, $M_{\mathrm{c}}>10 M_{\mathrm{c} \__{-} \mathrm{SiH}}$ for the elastomers with MCR-V21 side chains. The large differences 251 between $M_{\mathrm{c}}$ and $M_{\mathrm{c}_{-} \text {SiH }}$ can be explained by the preferentially intramolecular reactions of the multi252 functional bottle-brush chains, which result in a large fraction of elastically inactive loops and dan253 gling. ${ }^{45}$ Figure $5 \mathrm{~b}$ shows the compressibility of the bottle-brush elastomer Ela_HMS-064_MCR254 V21_R1.05 compared to that of the conventional elastomer Ref_DMS-V41. The bottle-brush elasto255 mer is compressed to a strain of $88 \%$ under a pressure of $0.16 \mathrm{MPa}$, while the conventional elasto256 mer only shows a compression strain of $19 \%$ under the same pressure. Importantly, despite the 257 large compression strain imposed on the bottle-brush elastomer, it recovers to its initial state al258 most instantaneously upon pressure being released, displaying superior elasticity compared to nor259 mal soft elastomers, which often recover only partially. 
Table 3. Specifications for studied soft silicone elastomers.

\begin{tabular}{|l|l|l|l|l|l|}
\hline Samples & $R$ & $\begin{array}{l}M_{\mathrm{HMS}} \\
(\mathrm{kDa})\end{array}$ & $\begin{array}{l}M_{\mathrm{MCR}-\mathrm{V}} \\
(\mathrm{kDa})\end{array}$ & $\begin{array}{l}M_{\mathrm{C} \_\mathrm{SiH}} \\
(\mathrm{kDa})\end{array}$ & $\begin{array}{l}M_{\mathrm{c}} \\
(\mathrm{kDa})\end{array}$ \\
\hline Ela_HMS-064_MCR-V21_R1.05 & 1.05 & 60 & 6 & 130 & 631 \\
\hline Ela_HMS-064_MCR-V21_R1.20 & 1.20 & 60 & 6 & 42 & 525 \\
\hline Ela_HMS-064_MCR-V21_R1.50 & 1.50 & 60 & 6 & 18 & 224 \\
\hline Ela_HMS-064_MCR-V25_R1.05 & 1.05 & 60 & 23 & 342 & 543 \\
\hline
\end{tabular}
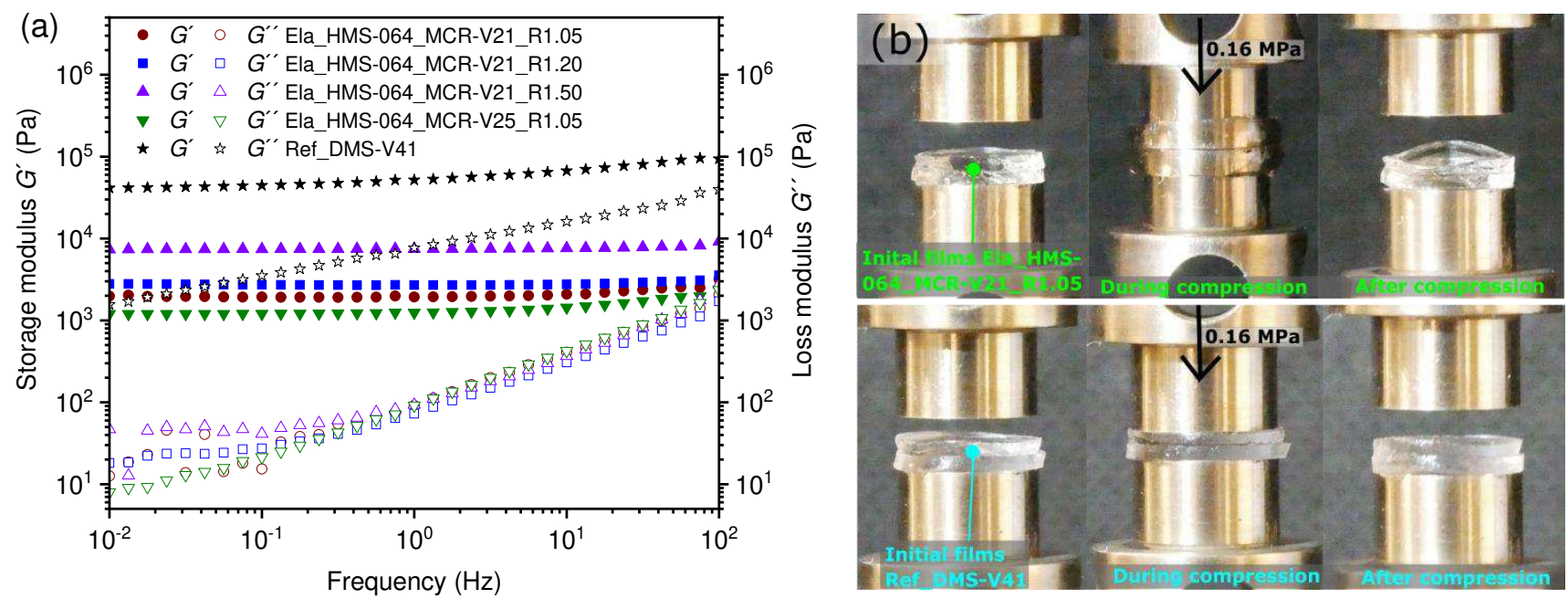

262 Figure 5. (a) Frequency dependence of storage and loss moduli of extremely soft silicone elastomers and a con-

263 ventional silicone elastomer measured at room temperature. (b) Two stacked extremely soft specimens $(8 \mathrm{~mm}$ in 264 diameter) are compressed to a strain of $88 \%$ by a pressure of $0.16 \mathrm{MPa}$ (the excess polymer is displaced up and 265 down the sides of the geometries). After the pressure is released, the films are recovered from the compressed state. 266 In comparison, two stacked conventional specimens (8 $\mathrm{mm}$ in diameter) were compressed to a strain of only $19 \%$ 267 under the same pressure. 
combined with a platinum-catalyzed reaction of telechelic/multi-hydride functional PDMS, without

272

273

274

275

276

277

278

279

280

281

282

283

284

285

286

287

288

289

290

291

292

293

294

using any additional cross-linker. The mechanism of the curing reaction is consistent with platinummediated crosslinking of hydrosilanes in the presence of trace water and oxygen, and thus may be considered a side-reaction in conventional formulations. Compared with classical curing chemistry-i.e., hydrosilylation reaction-Si-H crosslinking in the presence of moisture and oxygen proceeds much more slowly, thereby providing formulations with an inherent delayed crosslinking opportunity and allowing the preparation of highly diverse networks using simple one-pot reactions. Highly stretchable silicone elastomers and extremely soft silicone elastomers were developed by combining this curing chemistry with hydrosilylation reactions: the fast hydrosilylation reactions controlled the size and structures of network strands, after which elastomers were created through the much slower crosslinking of Si-H functional groups. Specifically, highly stretchable silicone elastomers were prepared by creating highly entangled (long-chain) silicone elastomers from the reaction between telechelic Si-H functional PDMS and telechelic vinyl functional PDMS. Tensile strains could be tailored from $1500 \%$ to $2800 \%$ by varying precursor length and the molar ratio of Si-H-tovinyl groups. We demonstrated a 180-fold extension in area by biaxial stretch for one such highly stretchable silicone elastomer. Extremely soft silicone elastomers were made by creating bottlebrush silicone elastomers from the reaction between multi-Si-H functional PDMS and mono-vinyl functional PDMS. The shear moduli of the prepared bottle-brush elastomers could be adjusted from $1.2 \mathrm{kPa}$ to $7.4 \mathrm{kPa}$ by changing the molar ratio of reactive groups and the side chain lengths.

Both highly stretchable silicone elastomers and extremely soft silicone elastomers can be easily prepared via one-pot reactions using commercial precursors. In addition to enabling the preparation of highly stretchableorextremely soft elastomers, the general methodology based on slow crosslinking presented here enables the easy development of silicone elastomers with a wide range of functionalities. 
297 Supporting information is available online

298

299 Corresponding Author

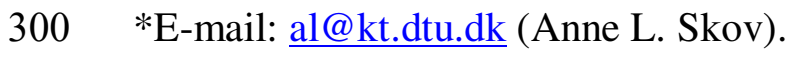

301

302

\section{Author Contributions}

303 The manuscript was written through contributions of all authors.

304

305

Notes

306 The authors declare no competing financial interest.

307

ACKNOWLEDGMENT

Pengpeng Hu acknowledges the financial support from China Scholarship Council (CSC, 201804910748) and Department of Chemical and Biochemical Engineering, Technical University of Denmark.

\section{REFERENCES}

313 (1) Son, D.; Kang, J.; Vardoulis, O.; Kim, Y.; Matsuhisa, N.; Oh, J. Y.; To, J. W.; Mun, J.; Katsumata, T.; Liu, Y.; McGuire, A. F.; Krason, M.; Molina-Lopez, F.; Ham, J.; Kraft, U.; Lee, Y.; Yun, Y.; Tok, J. B.; Bao, Z. An Integrated Self-Healable Electronic Skin System Fabricated via Dynamic Reconstruction of a Nanostructured Conducting Network. Nat. Nanotechnol. 2018, 13 (11), $1057-1065$.

(2) Kim, D. H.; Ahn, J. H.; Won, M. C.; Kim, H. S.; Kim, T. H.; Song, J.; Huang, Y. Y.; Liu, Z.; Lu, 
C.; Rogers, J. A. Stretchable and Foldable Silicon Integrated Circuits. Science 2008, 320 (5875), $507-511$.

Pelrine, R.; Kornbluh, R.; Pei, Q.; Joseph, J. High-Speed Electrically Actuated Elastomers with Strain Greater than 100\%. Science 2000, 287 (5454), 836-839.

van Erp, R.; Soleimanzadeh, R.; Nela, L.; Kampitsis, G.; Matioli, E. Co-Designing Electronics with Microfluidics for More Sustainable Cooling. Nature 2020, 585 (7824), 211-216.

(6) Ilami, M.; Bagheri, H.; Ahmed, R.; Skowronek, E. O.; Marvi, H. Materials, Actuators, and Sensors for Soft Bioinspired Robots. Adv. Mater. 2020, 33(19), 2003139.

(7) Miriyev, A.; Stack, K.; Lipson, H. Soft Material for Soft Actuators. Nat. Commun. 2017, 8 (1), 18.

(8) Marciniec, B.; Maciejewski, H.; Pietraszuk, P. P. Hydrosilylation: A Comprehensive Review on Recent Advances; Springer: Poland, 2013; Vol. 1.

(9) Kuhn, W. Dependence of the Average Transversal on the Longitudinal Dimensions of Statistical Coils Formed by Chain Molecules. J. Polym. Sci. 1946, 1 (5), 380-388.

(10) Vaicekauskaite, J.; Mazurek, P.; Vudayagiri, S.; Skov, A. L. Mapping the Mechanical and Electrical Properties of Commercial Silicone Elastomer Formulations for Stretchable Transducers. J. Mater. Chem. C 2020, 8, 1273.

(11) De Gennes, P. G.; Leger, L. Dymanics of Entangled Polymer Chains. Ann. Rev. Phys. Chem 1982, $33,49-61$.

(12) Kohjiya, S.; Urayama, K.; Ikeda, Y. Poly(Siloxane) Network of Ultra-High Elongation. Kautschuk Gummi Kunststoffe 1997, 50 (12), 868-870. 
(13) Li, C. H.; Wang, C.; Keplinger, C.; Zuo, J. L.; Jin, L.; Sun, Y.; Zheng, P.; Cao, Y.; Lissel, F.; Linder, C.; You, X.; Bao, Z. A Highly Stretchable Autonomous Self-Healing Elastomer. Nat. Chem. 2016, 8 (6), 618-624.

(14) Hayashi, M.; Noro, A.; Matsushita, Y. Highly Extensible Supramolecular Elastomers with Large Stress Generation Capability Originating from Multiple Hydrogen Bonds on the Long Soft Network Strands. Macromol. Rapid Commun. 2016, 37 (8), 678-684.

(15) Goff, J.; Sulaiman, S.; Arkles, B.; Lewicki, J. P. Soft Materials with Recoverable Shape Factors from Extreme Distortion States. Adv. Mater. 2016, 28 (12), 2393-2398.

(16) Hu, P.; Huang, Q.; Madsen, J.; Skov, A. L. Soft Silicone Elastomers with No Chemical CrossLinking and Unprecedented Softness and Stability. Electroactive Polymer Actuators and Devices (EAPAD) XXII, SPIE 2020, 11375

(17) Hu, P.; Madsen, J.; Huang, Q.; Skov, A. L. Elastomers without Covalent Cross-Linking: Concatenated Rings Giving Rise to Elasticity. ACS Macro Lett. 2020, 9 (10), 1458-1463.

(18) Heinrichs, V.; Dieluweit, S.; Stellbrink, J.; Pyckhout-Hintzen, W.; Hersch, N.; Richter, D.; Merkel, R. Chemically Defined, Ultrasoft PDMS Elastomers with Selectable Elasticity for Mechanobiology. PLoS One 2018, 13 (4), 1-22.

(19) Lenhart, J. L.; Cole, P. J. Adhesion Properties of Lightly Crosslinked Solvent-Swollen Polymer Gels. J. Adhes. 2006, 82 (10), 945-971.

(20) Larsen, A. L.; Sommer-Larsen, P.; Hassager, O. How to Tune Rubber Elasticity. Electroactive Polymer Actuators and Devices (EAPAD), SPIE 2004, 5385

(21) Daniel, W. F. M.; Burdyńska, J.; Vatankhah-Varnoosfaderani, M.; Matyjaszewski, K.; Paturej, J.; Rubinstein, M.; Dobrynin, A. V.; Sheiko, S. S. Solvent-Free, Supersoft and Superelastic Bottlebrush Melts and Networks. Nat. Mater. 2016, 15 (2), 183-189.

(22) Cai, L. H.; Kodger, T. E.; Guerra, R. E.; Pegoraro, A. F.; Rubinstein, M.; Weitz, D. A. Soft Poly(Dimethylsiloxane) Elastomers from Architecture-Driven Entanglement Free Design. Adv. 
Mater. 2015, 27 (35), 5132-5140.

369

370

(23) Reynolds, V. G.; Mukherjee, S.; Xie, R.; Levi, A. E.; Atassi, A.; Uchiyama, T.; Wang, H.; Chabinyc, M. L.; Bates, C. M. Super-Soft Solvent-Free Bottlebrush Elastomers for Touch Sensing. Mater. Horizons 2020, 7 (1), 181-187.

(24) Wong, M. Y.; Schneider, A. F.; Lu, G.; Chen, Y.; Brook, M. A. Autoxidation: Catalyst-Free Route to Silicone Rubbers by Crosslinking Si-H Functional Groups. Green Chem. 2019, 21 (23), 64836490.

(25) Brook, M. A. Silicon in Organic, Organometallic, and Polymer Chemistry; Wiley: Canada, 1999; pp 176.

(26) Lukevics E.; Dzintara M. The alcoholysis of Hydrosilanes. Journal of Organometallic Chemistry 1985, 295(3), 265-315.

(27) Chauhan, B. P. S.; Sarkar, A.; Chauhan, M.; Roka, A. Water as Green Oxidant: A Highly Selective Conversion of Organosilanes to Silanols with Water. Appl. Organomet. Chem. 2009, 23 (10), 385390.

(28) Hill, D. J. T.; Preston, C. M. L.; Whittaker, A. K. NMR Study of the Gamma Radiolysis of Poly(Dimethyl Siloxane) under Vacuum at 303 K. Polymer 2002, 43 (4), 1051-1059.

(29) Patai, S.; Rappoport, Z. The Chemistry of Organic Silicon Compounds. John Wiley \&Sons: Singapore, 1989, pp 517, 523.

(30) Israëli, Y.; Lacoste, J.; Cavezzan, J.; Lemaire, J. Photo-Oxidation of Polydimethylsiloxane Oils Part III-Effect of Dimethylene Groups. Polym. Degrad. Stab. 1993, 42 (3), 267-279.

(31) Helbich, T.; Lyuleeva, A.; Höhlein, I. M. D.; Marx, P.; Scherf, L. M.; Kehrle, J.; Fässler, T. F.; Lugli, P.; Rieger, B. Radical-Induced Hydrosilylation Reactions for the Functionalization of TwoDimensional Hydride Terminated Silicon Nanosheets. Chem. - A Eur. J. 2016, 22 (18), 6194-6198.

(32) Yang, Z.; Iqbal, M.; Dobbie, A. R.; Veinot, J. G. C. Surface-Induced Alkene Oligomerization: Does Thermal Hydrosilylation Really Lead to Monolayer Protected Silicon Nanocrystals? J. Am. Chem. 
Soc. 2013, 135 (46), 17595-17601.

(33) Xiao, R.; Zammit, I.; Wei, Z.; Hu, W.-P.; MacLeod, M.; Spinney, R. Kinetics and Mechanism of the Oxidation of Cyclic Methylsiloxanes by Hydroxyl Radical in the Gas Phase: An Experimental and Theoretical Study. Environmental Science \& Technology 2015, 49(22), 13322-13330.

(34) Sommerlada, R.; Parlar, H.; Wrobel, D.; Kochs, P. Product Analysis and Kinetics of the Gas-Phase Reactions of Selected Organosilicon Compounds with OH Radicals Using a Smog Chamber-Mass Spectrometer System. Environmental Science \& Technology 1993, 27(12), 2435-2440.

(35) Tsukada, N.; Hartwig, J. F. Intermolecular and Intramolecular, Platinum-Catalyzed, Acceptorless Dehydrogenative Coupling of Hydrosilanes with Aryl and Aliphatic Methyl C-H Bonds. J. Am. Chem. Soc. 2005, 127(14), 5022-5023.

(36) Corey, J. Y. Reactions of Hydrosilanes with Transition Metal Complexes. Chemical Reviews 2016, 116(19), 11291-11435.

(37) Nagai, Y. Hydrosilanes as Reducing Agents. A Review. Org. Prep. Proced. Int. 1980, 12 (1-2), $13-48$.

(38) Lewis, L. N. On the Mechanism of Metal Colloid Catalyzed Hydrosilylation: Proposed Explanations for Electronic Effects and Oxygen Cocatalysis. J. Am. Chem. Soc. 1990, 112 (16), 5998-6004.

(39) Onopchenko, A.; Sabourin, E. T. Activation of Platinum Catalysts with Oxygen To Enhance Hydrosilylation of Unactivated Alkyl-, Dialkyl-, and Trialkylsilanes with 1-Alkenes: Synthesis of Tetraalkylsilanes. J. Org. Chem. 1987, 52 (18), 4118-4121.

(40) Fetters, L. J.; Lohse, D. J.; Richter, D.; Witten, T. A.; Zirkel, A. Connection between Polymer Molecular Weight, Density, Chain Dimensions, and Melt Viscoelastic Properties. Macromolecules 1994, 27 (17), 4639-4647.

(41) Abbasi, M.; Faust, L.; Wilhelm Abbasi, M. M.; Faust, L.; Wilhelm, M. Comb and Bottlebrush Polymers with Superior Rheological and Mechanical Properties. Adv. Mater. 2019, 31(26), 1806484. 
418 (42) Geliebter, A.; Melton, P. M.; McCray, R. S.; Gage, D.; Heymsfield, S. B.; Abiri, M.; Hashim, S.

A. Clinical Trial of Silicone-Rubber Gastric Balloon to Treat Obesity. Int. J. Obes. 1991, 15 (4), 259-266.

(43) Wang, S.; Xu, J.; Wang, W.; Wang, G. J. N.; Rastak, R.; Molina-Lopez, F.; Chung, J. W.; Niu, S.; Feig, V. R.; Lopez, J.; Lei, T.; Kwon, S.; Kim, Y.; Foudeh, A. M.; Ehrlich, A.; Gasperini, A.; Yun, Y.; Murmann, B.; Tok, J. B.; Bao, Z. Skin Electronics from Scalable Fabrication of an Intrinsically Stretchable Transistor Array. Nature 2018, 555 (7694), 83-88.

(44) Shim, H. J.; Sunwoo, S. H.; Kim, Y.; Koo, J. H.; Kim, D. H. Functionalized Elastomers for 426 Intrinsically Soft and Biointegrated Electronics. Adv. Healthc. Mater. 2021, 2002105, 1-33.

(45) Aharoni, S. M. Intramolecular Crosslinking. Die Angew. Makromol. Chemie 1977, 62 (1), 115428 133.

429 


\section{Supporting information}

432 Highly stretchable or extremely soft silicone elastomers ? One reaction

433 to make them all - from easily available materials!

434

435 Pengpeng $\mathrm{Hu}$, Jeppe Madsen, and Anne Ladegaard Skov*

436 Department of Chemical and Biochemical Engineering, Technical University of Denmark

437 Søltofts Plads 227, Kgs., Lyngby, 2800, Denmark

438 E-mail: al@kt.dtu.dk 
440 Materials Information of chemicals used in this studies is shown in Table S1, in which all the chemicals 441 were purchased from Gelest, except that Catalyst 511was purchased from Hanse Chemie. As a precursor 442 polymer for condition controlling experiments, DMS-H11 (10 mL) was diluted in hexane $(20 \mathrm{~mL}, \geq 95 \%$, 443 Sigma-Aldrich) and dried with silica gel (5 g, particle size of 63-200 $\mu \mathrm{m}$, high-purity grade, Sigma-Al444 drich) in a sealed flask at a room temperature for 2 days. The upper layer was transferred into a dried flask 445 through a syringe mounted with a filter. Subsequently, the hexane was thoroughly distilled under a vac446 uum pressure condition at room temperature for $6 \mathrm{~h}$. Red pigment (PGRED01, 50\% in silicone oil) was 447 purchased from Gelest.

448 Silicone elastomers prepared from hydrosilane (Si-H) containing PDMS. All the telechelic Si-H func449 tional PDMS and multi-Si-H functional PDMS in Table S1 were used to prepare silicone elastomers, 450 respectively. A representative procedure is as follows: DMS-H11 $\left(10 \mathrm{~g}, 1.00 \times 10^{-2}\right.$ mol $)$ was mixed with 451 catalyst SIP $6830.3\left(2 \mathrm{mg}, 3.08 \times 10^{-7} \mathrm{~mol}\right)$ using a speed mixer (DAC150FVZ, Hauschild Co.) at 3000 $452 \mathrm{rpm}$ for $2 \mathrm{~min}$. The mixture was poured into a mold and placed in an oven at $100^{\circ} \mathrm{C}$ for $24 \mathrm{~h}$.

453 Highly stretchable silicone elastomers and extremely soft silicone elastomers Vinyl functional PDMS 454 and catalyst SIP $6830.3\left(2 \mathrm{mg}, 3.08 \times 10^{-7} \mathrm{~mol}\right)$ were well mixed using a speed mixer. Subsequently, Si455 H functional PDMS was added into the mixture and well-mixed. The final mixture was poured on a mold 456 and placed in an oven at $100^{\circ} \mathrm{C}$ for $24 \mathrm{~h}$. The prepared elastomers listed in Table $\mathbf{S 2}$ are named according 457 to the precursor polymer used.

458 Conventional silicone elastomers Part A and part B were prepared before the curing reaction. For a 459 reference sample of Ref_DMS-V25, part A was prepared by mixing DMS-V25 (5 g, $\left.3.3 \times 10^{-4} \mathrm{~mol}\right)$

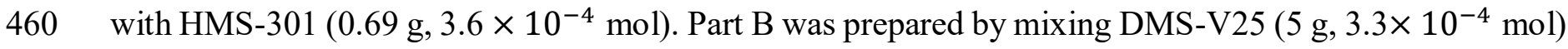
461 with catalyst $511\left(2 \mathrm{mg}, 1.0 \times 10^{-7} \mathrm{~mol}\right)$. For a reference sample of Ref_DMS-V41, part A was prepared 
by mixing DMS-V41 (10 g, $\left.1.5 \times 10^{-4} \mathrm{~mol}\right)$ with HMS-301 $\left(0.14 \mathrm{~g}, 7.3 \times 10^{-5} \mathrm{~mol}\right)$. Part B was pre-

463 pared by mixing DMS-V41 (4.8 g, $\left.7.7 \times 10^{-5} \mathrm{~mol}\right)$ with catalyst $511\left(3 \mathrm{mg}, 1.5 \times 10^{-7} \mathrm{~mol}\right)$. Parts A 464 and B were then mixed together using a speed mixer at $3000 \mathrm{rpm}$ for $30 \mathrm{~s}$. The final mixture was poured 465 on the surface of a polyethylene terephthalate (PET) substrate and evenly distributed by applying an au466 tomatic applicator. The PET substrate together with the mixture was placed in an oven at $100^{\circ} \mathrm{C}$ for $5 \mathrm{~h}$.

Table S1. Information of chemicals used in this study

\begin{tabular}{|c|c|c|c|c|}
\hline Type of chemical & Chemical structure & Abbreviation & $M_{n}^{a}(k D a)$ & $\mathbf{D}_{\mathbf{M}}^{\mathrm{b}}$ \\
\hline \multirow{4}{*}{ Telechelic Si-H functional } & \multirow{4}{*}{$\mathrm{H}_{2} \mathrm{C}=\mathrm{CH}\left(\begin{array}{l}\mathrm{CH}_{3} \\
-\mathrm{Si}-\mathrm{O} \\
\mathrm{CH}_{3}\end{array}\right)_{\mathrm{n}}^{\mathrm{Si}-\mathrm{H}} \mathrm{CH}_{3}^{\mathrm{CH}_{3}}$} & DMS-H11 & 1 & 1.3 \\
\hline & & DMS-H21 & 6 & 1.6 \\
\hline & & DMS-H25 & 14 & 1.5 \\
\hline & & DMS-H31 & 24 & 1.5 \\
\hline Mono-Si-H functional PDMS & & MCR-H21 & 7 & 1.1 \\
\hline \multirow{2}{*}{ Multi-Si-H functional PDMS } & \multirow{2}{*}{ 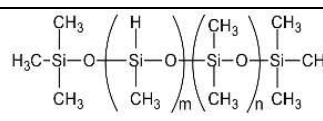 } & HMS-301c & 2 & - \\
\hline & & HMS-064c & 60 & - \\
\hline \multirow{3}{*}{ Telechelic vinyl func } & \multirow{3}{*}{$\mathrm{CH}_{3} \backslash \mathrm{CH}_{3}$} & DMS-V22 & 8 & 2.1 \\
\hline & & DMS-V25 & 14 & 1.5 \\
\hline & & DMS-V41 & 35 & 2.0 \\
\hline \multirow{2}{*}{ Mono-vinyl functional PDMS } & \multirow{2}{*}{ 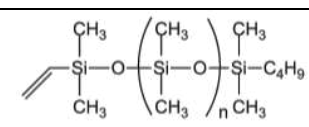 } & MCR-V21 & 6 & 1.1 \\
\hline & & MCR-V25 & 23 & 1.3 \\
\hline \multicolumn{2}{|l|}{$\begin{array}{l}\text { Platinum-divinyl tetramethyl- } \\
\text { disiloxane complex, } 3.0 \mathrm{wt} \% \mathrm{Pt}\end{array}$} & SIP 6830.3 & - & - \\
\hline $\begin{array}{l}\text { Platinum cyclo-vinylmethyl si- } \\
\text { loxane complex, } 1.0 \mathrm{wt} \% \mathrm{Pt}\end{array}$ & - & Catalyst 511 & - & - \\
\hline
\end{tabular}

a: Number average molecular weight. b: Poly-dispersity index. c: Concentrations of Si-H groups on HMS-301 and HMS-064 were determined to be $3.74 \mathrm{~mol} / \mathrm{kg}$ and $0.830 \mathrm{~mol} / \mathrm{kg}$, respectively, based on integrations of ${ }^{1} \mathrm{H}$ spectra. 
Table S2. Formulations of preparing highly stretchable and extremely soft silicone elastomers

\begin{tabular}{|c|c|c|c|c|}
\hline \multirow{2}{*}{ Sample } & \multicolumn{2}{|c|}{ Si-H functional PDMS } & \multicolumn{2}{c|}{ Vinyl functional PDMS } \\
\cline { 2 - 4 } & Mass (g) & Molar amount of Si-H & Mass (g) & nyl group (mol) \\
\hline Ela_DMS-H21_DMS-V22_R1.05 & 4.46 & $1.55 \times 10^{-3}$ & 5.54 & $1.47 \times 10^{-3}$ \\
\hline Ela_DMS-H21_DMS-V22_R1.10 & 4.57 & $1.59 \times 10^{-3}$ & 5.43 & $1.44 \times 10^{-3}$ \\
\hline Ela_DMS-H21_DMS-V22_R1.15 & 4.68 & $1.63 \times 10^{-3}$ & 5.32 & $6.92 \times 10^{-4}$ \\
\hline Ela_DMS-H25_DMS-V25_R1.05 & 5.16 & $7.27 \times 10^{-4}$ & 8.61 & $1.10 \times 10^{-3}$ \\
\hline Ela_HMS_064-MCR-V21_R1.05 & 1.39 & $1.16 \times 10^{-3}$ & 8.44 & $1.08 \times 10^{-3}$ \\
\hline Ela_HMS_064-MCR-V21_R1.20 & 1.56 & $1.30 \times 10^{-3}$ & 8.12 & $1.04 \times 10^{-3}$ \\
\hline Ela_HMS_064-MCR-V21_R1.50 & 1.88 & $1.56 \times 10^{-3}$ & & $4.15 \times 10^{-4}$ \\
\hline Ela_HMS_064-MCR-V25_R1.05 & 0.52 & $4.36 \times 10^{-4}$ & & \\
\hline
\end{tabular}

Condition controlling experiments Before reactions, glassware was dried at $120^{\circ} \mathrm{C}$ overnight. Platinum catalyst SIP $6830.3(1 \mathrm{mg})$ and dried DMS-H11 $(1 \mathrm{~g})$ were added in $50 \mathrm{~mL}$ - round-bottom flasks sealed with a rubber septum and a stopcock adapter. The mixture was well mixed by vigorous shaking. Four reactions under four different atmospheres were created as follows: (a) Dry $\mathrm{N}_{2}$ atmosphere was created by evacuating air from the flask and then backfilling with dry $\mathrm{N}_{2}$ for 4 cycles before the addition of the precursor polymer and the catalyst. (b) Wet $\mathrm{N}_{2}$ atmosphere was created as same as (a) but adding 3 drops of water in the flask and dispersing into the precursor polymer by vigorous shaking. (c) Dry air was created as same as protocol (a) but replacing the dry $\mathrm{N}_{2}$ with dry air. (d) Wet air was created as same as protocol (b) but replacing the dry $\mathrm{N}_{2}$ with dry air. Subsequently, the four flasks were heated at $100{ }^{\circ} \mathrm{C}$ for $48 \mathrm{~h}$.

479 The resulting liquid products were analyzed by ${ }^{1} \mathrm{H}$ nuclear magnetic resonance (NMR) and size-exclusion 480 chromatography (SEC).

481 Kinetics study Two sets of reactions (a) MCR-H21 (2 g) mixed with catalyst SIP6830.3 (2 mg), and (b) 482 MCR-H21 (1 g) mixed with MCR-V21 (1 g) and SIP6830.3 (2 mg) were run in an oven at 100 ${ }^{\circ} \mathrm{C}$. Samples 
were taken from the reaction (a) at reaction time of $10 \mathrm{~min}, 30 \mathrm{~min}, 60 \mathrm{~min}, 180 \mathrm{~min}$ and $360 \mathrm{~min}$. Samples

were taken from reaction (b) at reaction time of $0.5 \mathrm{~min}, 1 \mathrm{~min}, 2 \mathrm{~min}, 5 \mathrm{~min}$ and $30 \mathrm{~min}$. All the samples were cooled down immediately by using dry ice, and analyzed by ${ }^{1} \mathrm{H}$ NMR and SEC.

Uniaxial tensile test Stress-strain responses of elastomers were measured using an Instron 3340 materials testing system (INSTRON, US) at a crosshead speed of $500 \mathrm{~mm} \mathrm{~min}^{-1}$. Specimens were cut with a dumbbell shape according to ASTM D-638 Type V (width: $3.18 \mathrm{~mm}$; length: $9.53 \mathrm{~mm}$; thickness: $1 \mathrm{~mm}$ ).

Elastic moduli were determined by linear fitting of the stress-strain data at a strain range of $0-10 \%$.

Biaxial tension test An elastomer film $(1 \mathrm{~mm} \times 50 \mathrm{~mm} \times 50 \mathrm{~mm})$ was marked with a $1 \mathrm{~cm}$-square in the 491 center by using red pigment (PGRED01, 50\% in silicone oil, Gelest Inc.). The film was biaxially stretched 492 until it was close to break. The stretched film was placed above a grid pad on a table in order to estimate 493 the size changes of the red square, then it covered the surface of a standard football with a $21 \mathrm{~cm}$-diameter.

494 Linear viscoelasticity (LVE) Specimen LVE was measured by a strain-controlled rheometer ARES G2 495 (TA Instruments), using small amplitude oscillatory shear (SAOS). Specimens with a thickness of $\sim 1 \mathrm{~mm}$ 496 were cut into cylinders with $8 \mathrm{~mm}$-diameter. The shear strain amplitude was fixed to $1 \%$. For highly 497 stretchable elastomers, frequency sweeps from $1.6 \cdot 10^{1}$ to $1.6 \cdot 10^{-3} \mathrm{~Hz}$ were conducted at $21^{\circ} \mathrm{C}$ and $200^{\circ} \mathrm{C}$, 498 respectively. Time-temperature superposition was used to create master curves based on a reference tem499 perature of $21^{\circ} \mathrm{C}$. For extremely soft elastomers, a frequency sweep was performed from $1.0 \cdot 10^{2}$ to 500 $1.0 \cdot 10^{-2} \mathrm{~Hz}$ at $21^{\circ} \mathrm{C}$.

501 Time sweep in LVE region. Modulus complex during curing of elastomers was measured by a strain502 controlled rheometer AR-2000 (TA Instruments). The mixture of precursor polymers with platinum cat503 alysts was sandwiched by two geometries of instruments. The thickness of the mixture layer is around 0.5 $504 \mathrm{~mm}$ and the diameter is the plates is $20 \mathrm{~mm}$. Oscillatory experiments were performed with a controlled 505 temperature of $100^{\circ} \mathrm{C}$, a controlled strain of $1 \%$, and a constant shear frequency of $1 \mathrm{~Hz}$. 
506 Compression test Two pieces of cylinder elastomers ( $8 \mathrm{~mm}$ in didameter) were stacked with a thickness

507 of around $2 \mathrm{~mm}$. Rheometer ARES G2 was used to compress the elastomers by applying two round plates

508 (8 $\mathrm{mm}$ in diameter). Applied forces and gaps between plates were recorded during the compression.

509 SEC measurement SEC was performed on a Tosoh EcoSEC HLC8320GPC instrument equipped with 510 RI and UV detectors and SDV Linear S columns from Polymer Standards Service (PSS). Samples were 511 run in toluene at $35^{\circ} \mathrm{C}$ at a rate of $1 \mathrm{~mL} \mathrm{~min}^{-1}$. Molecular weights and $\bigoplus_{\mathrm{M}}$ were calculated using WinGPC 512 Unity 7.4.0 software and standard linear PDMS were acquired from PSS.

513 NMR measurement ${ }^{1} \mathrm{H}$ NMR spectra of samples were performed on a Bruker $300 \mathrm{MHz}$ spectrometer 514 on $50 \mathrm{mg} \mathrm{mL}^{-1}$ solutions in $\mathrm{CDCl}_{3} .{ }^{29} \mathrm{Si}$ solid-state NMR MAS spectra of investigated elastomers were 515 acquired on a Bruker Avance III HD spectrometer operating at a magnetic field of $14.05 \mathrm{~T}\left(v_{\mathrm{L}}\left({ }^{29} \mathrm{Si}\right)=\right.$ $516119.2 \mathrm{MHz}$ ) and equipped with a $4 \mathrm{~mm} \mathrm{CP} / \mathrm{MAS}$ broadband probe. The spectra were acquired with a 517 spinning frequency of $6 \mathrm{kHz}$, a $\pi / 2$ pulse of $4.75 \mathrm{~ms}$, an acquisition time of $35 \mathrm{~ms}$ and 10 seconds of 518 interscan delay. This was determined to be sufficient for full relaxation of the two observed signals for 519 elastomers. High-power ${ }^{1} \mathrm{H}$ SPINAL64 decoupling $\left(v_{\mathrm{RF}}=100 \mathrm{kHz}\right)$ was employed during acquisition. 520 The prepared elastomers were cut into smaller pieces and packed in $4 \mathrm{~mm}$ o.d. zirconia rotors. Chemical 521 shifts are reported relative to TMS (0.0 ppm). High-resolution ${ }^{29} \mathrm{Si}$ NMR spectrum of a precursor PDMS 522 (liquid state) was acquired on a Bruker Avance II spectrometer operating at a magnetic field of $9.4 \mathrm{~T}\left(v_{\mathrm{L}}\right.$ $\left.523\left({ }^{29} \mathrm{Si}\right)=79.495 \mathrm{MHz}\right)$ and equipped with a $5 \mathrm{~mm}$ BBFO probe. The NMR samples were prepared as524 received (i.e. no deuterated solvent was added) and chemical shifts are referenced using the lock-field 525 determined for a secondary $\mathrm{CDCl}_{3}$ sample. A Pi/6 pulse was used for excitation with an interscan delay 526 of 15 seconds. Inverse-gated $1 \mathrm{H}$ decoupling was applied during acquisition. Data were analyzed using 527 MestReNova-11. 
529 For a platinum-catalyzed reaction system of telechelic Si-H functional PDMS with telechelic vinyl func-

530 tional PDMS using a small excess of Si-H groups, both the hydrosilylation reaction between $\mathrm{Si}-\mathrm{H}$ and 531 vinyl groups and the crosslinking of $\mathrm{Si}-\mathrm{H}$ take place. Assuming the two reactions happen strictly in se532 quence, the hydrosilylation reaction results in extended chains, which are cross-linked into elastomers by 533 subsequent crosslinking of excess $\mathrm{Si}-\mathrm{H}$. According to mass balance equation:

$$
(R-1) M_{\text {extended }}=R M_{\mathrm{DMS}-\mathrm{H}}+M_{\mathrm{DMS}-\mathrm{V}}
$$

534 Where $M_{\mathrm{DMS}-\mathrm{H}}$ is the molecular weight of telechelic Si-H functional PDMS, $M_{\mathrm{DMS}-\mathrm{v}}$ is the molecular 535 weight of telechelic vinyl functional PDMS, $M_{\text {extended }}$ is the average molar mass of the extended network 536 strands and $R$ is the molar ratio of the $\mathrm{Si}-\mathrm{H}$ to vinyl functional groups. $M_{\text {extended }}$ is expressed as:

$$
M_{\text {extended }}=\frac{R M_{\mathrm{DMS}-\mathrm{H}}+M_{\mathrm{DMS}-\mathrm{V}}}{R-1}
$$

\section{Theoretical molecular weight between Si-H groups on intermediate bottlebrush polymers}

538 Assuming crosslinking of Si-H takes place strictly after the full grafting of side chains, molecular weight 539 between $\mathrm{Si}-\mathrm{H}$ groups on intermediate bottlebrush polymers $\left(M_{\mathrm{C}_{-} \mathrm{SiH}}\right)$ is expressed as equation $\mathrm{S} 5$.

$$
\begin{gathered}
f_{\mathrm{brush}}=\frac{R-1}{R} f \\
M_{\mathrm{brush}}=M_{\mathrm{HMS}}+\left(f-f_{\mathrm{brush}}\right) M_{\mathrm{MCR}-\mathrm{V}} \\
M_{\mathrm{c} \_ \text {SiH }}=\frac{M_{\mathrm{brush}}}{f_{\mathrm{brush}}+1}
\end{gathered}
$$

540 Where $M_{\text {brush }}$ and $f_{\text {brush }}$ are the molecular weight and number of Si-H groups of the intermediate 541 bottle-brush polymer. $f$ and $M_{\mathrm{HMS}}$ is the functionality and molecular weight of multi-Si-H functional 542 PDMS. $M_{\mathrm{HMS}-\mathrm{V}}$ is the molecular weight of mono-vinyl functional PDMS.

543 Calculation of molecular weights of bottle-brush network strands $\left(\boldsymbol{M}_{\mathbf{c}}\right)$

$544 M_{\mathrm{c}}$ are determined based on the measured shear moduli $(G)$ by equation S6. ${ }^{1}$ 


$$
M_{\mathrm{c}}=\frac{\rho R T \emptyset^{2}}{G}
$$

545 Where $\rho$ is the density of silicone elastomer. $R$ is the gas constant. $T$ is the absolute temperature. $\emptyset$ is the 546 gel fraction of elastomers. $G$ is the shear modulus of elastomers.

SUPPLEMENTARY FIGURES

549 Table S3 Integration of ${ }^{1} \mathrm{H}$ NMR spectra of a telechelic Si-H functional PDMS (DMS-H11) and its reac-

550 tion products after heating at $100^{\circ} \mathrm{C}$ for $48 \mathrm{~h}$ under dry $\mathrm{N}_{2}$, wet $\mathrm{N}_{2}$ and dry air conditions, respectively.

\begin{tabular}{|c|c|c|c|c|}
\hline \multirow{2}{*}{ Sample } & $\begin{array}{c}\mathbf{5 . 1 1} \mathbf{~ p p m ~ t o ~} \mathbf{4 . 5 5} \\
\mathbf{p p m}\end{array}$ & $\mathbf{3 . 5 2} \mathbf{p p m}$ to $4.34 \mathbf{p p m}$ & $\begin{array}{c}\mathbf{2 . 3 9} \mathbf{~ p p m ~ t o ~ 2 . 2 3} \\
\mathbf{p p m}\end{array}$ & $\mathbf{0 . 3 0} \mathbf{~ p p m ~ t o ~ 0 . 1 8 ~ p p m}$ \\
\cline { 2 - 5 } & $\mathrm{Si}-\mathrm{H}$ & $\mathrm{SiOC} H_{2} \mathrm{Si}$ & $\mathrm{Si}-\mathrm{O} H$ & $\mathrm{CH}_{3}$ except at the two ends \\
\hline DMS-H1 & 201.28 & 0 & 0 & 10000 \\
\hline Dry $\mathrm{N}_{2}$ & 188.02 & 0 & 1.17 & 10000 \\
\hline Wet $\mathrm{N}_{2}$ & 141.91 & 0 & 2.77 & 10000 \\
\hline Dry air & 94.84 & 1.36 & 0.51 & 10000 \\
\hline
\end{tabular}

551

552 Table S4 Integration of ${ }^{29}$ Si solid state NMR spectra of a telechelic Si-H functional PDMS (DMS-H11) 553 and solid elastomers prepared under normal air conditions.

\begin{tabular}{|c|c|c|c|c|}
\hline \multirow{2}{*}{ Sample } & $\begin{array}{c}\mathbf{9 . 0 8} \mathbf{p p m} \text { to 6.20 } \\
\mathbf{p p m}\end{array}$ & $\begin{array}{c}\mathbf{- 6 . 6 7} \mathbf{p p m} \text { to }- \\
\mathbf{8 . 0 8} \mathbf{~ p p m}\end{array}$ & $\mathbf{- 2 1 . 6 4 p p m}$ to $\mathbf{- 2 3 . 4 4} \mathbf{~ p p m}$ & $\mathbf{- 6 2 . 9 2} \mathbf{p p m}$ to -65.33 \\
& $\left(\mathrm{CH}_{3}\right)_{2} \mathrm{CH}_{2} \mathrm{SiO}$ & $\mathrm{Si}-\mathrm{H}$ & $\mathrm{SiOSi}$ & $\mathrm{CH}_{3} \mathrm{SiO}_{3}$ \\
\hline DMS-H11 & 0 & 19.56 & 100 & 0 \\
\hline Ela_DMS-H11 & 1.44 & 0 & 100 & 0.97 \\
\hline Ela_DMS-H21 & 0.43 & 0 & 100 & 1.19 \\
\hline
\end{tabular}




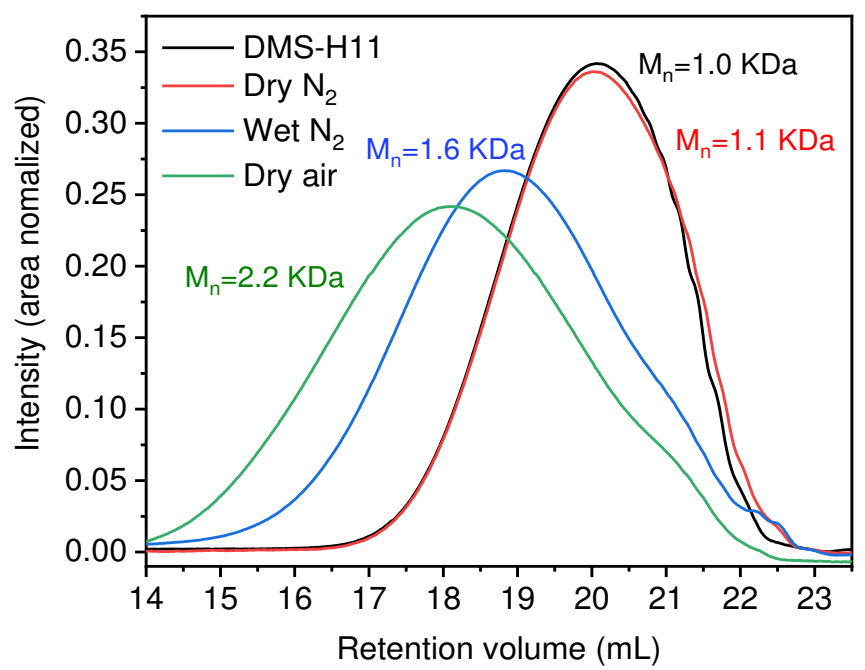

557 Figure S1. SEC curves of starting polymer DMS-H11 and its liquid products after heating at $100^{\circ} \mathrm{C}$ for $55848 \mathrm{~h}$ under dry $\mathrm{N}_{2}$, wet $\mathrm{N}_{2}$ and dry air atmospheres, respectively.
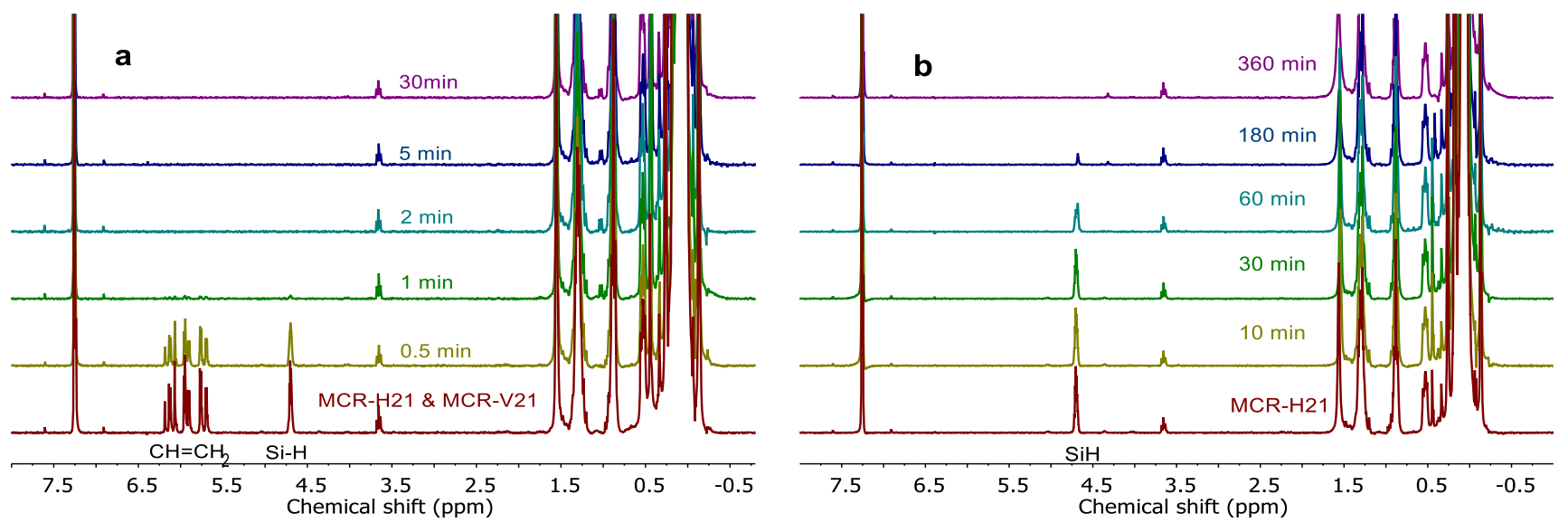

560 Figure S2. Evolutions of ${ }^{1} \mathrm{H}$ spectra over time for (a) the reaction of mono-Si-H functional PDMS, and 561 (b) hydrosilylation reaction between mono-Si-H functional PDMS with mono-vinyl functional PDMS . 


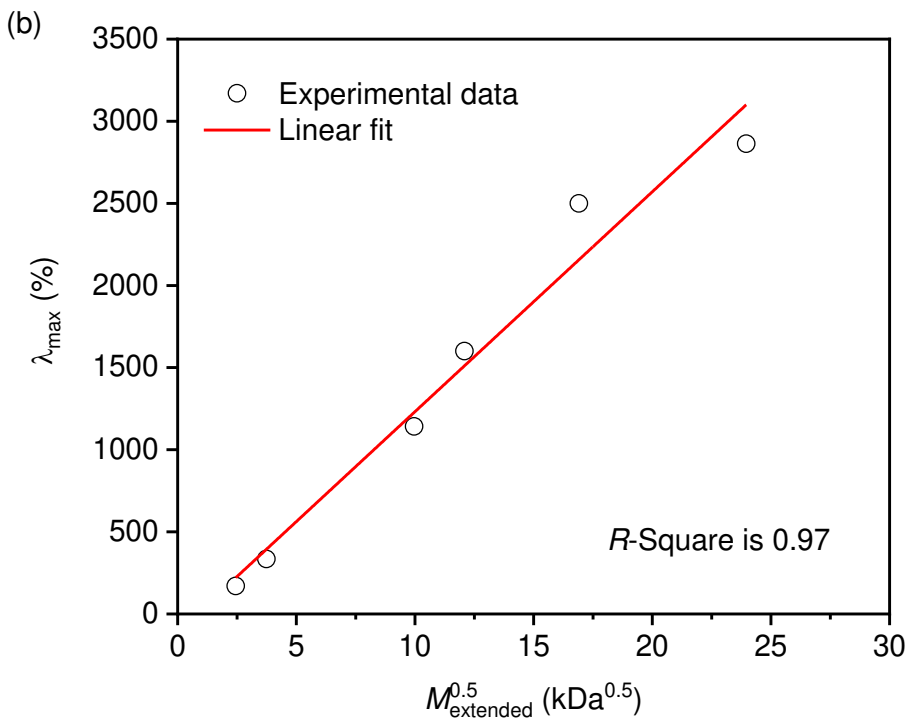

563 Figure S3. Linear fitting of $\lambda_{\max }$ and $M_{\text {extended }}^{0.5}$. For highly stretchable silicone elastomers, $M_{\text {extended }}$ is 564 the theoretical molar mass of precursor polymer calculated by Equation S2. For conventional silicone 565 elastomers Ref_DMS-V25 and Ref_DMS-V41, $M_{\text {extended }}$ approximately equals the molecular weight of 566 precursor polymers DMS-V25 and DMS-V41, respectively.

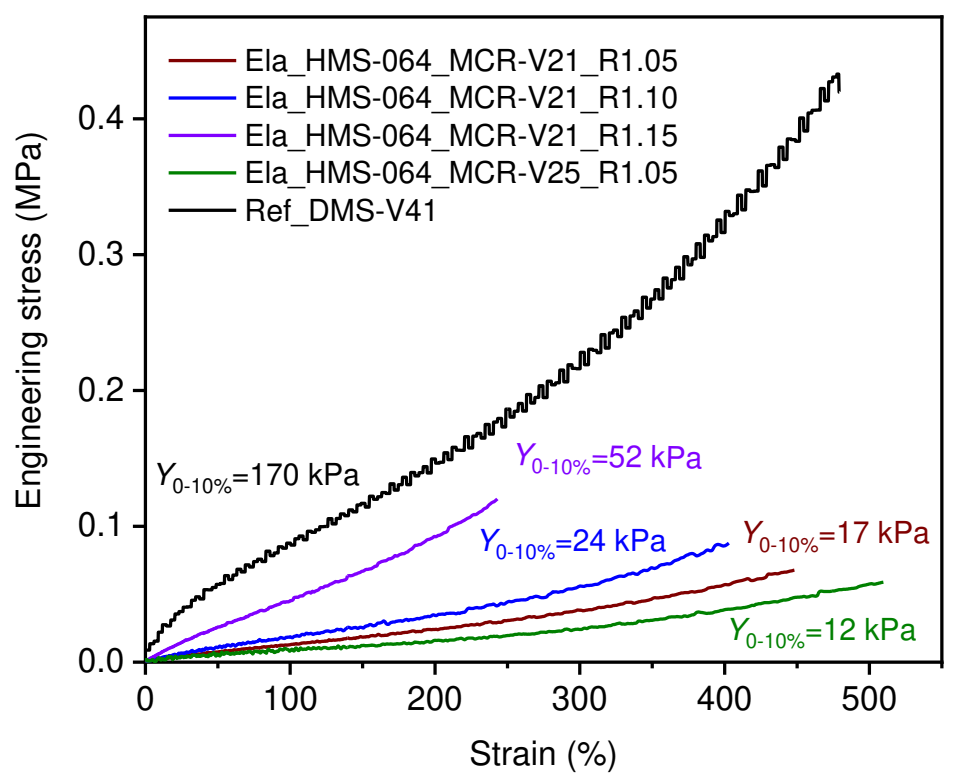

568 Figure S4. Uniaxial stress-strain curves of extremely soft silicone elastomers and a conventional silicone 569 elastomer. 
$571 \quad$ Reference

572 (1) Vasiliev, V. G.; Rogovina, L. Z.; Slonimsky, G. L. Dependence of Properties of Swollen and Dry 573 Polymer Networks on the Conditions of Their Formation in Solution. Polymer 1985, 26 (11), 1667$574 \quad 1676$. 